\title{
Systems Analysis Frameworks
}




\section{Studies in Management}

General Editor: SAMUEL EILSON, D.SC (ENG), PH.D, D.I.C, M.I.MECH.E, M.I.PROD.E. Professor of Industrial and Management Engineering, Imperial College, London

Network Analysis

for Planning and Scheduling

Exercises in Industrial Management A Series of Case Studies

Applied Queueing Theory

Mathematical Programming for

BUSINESS AND INDUSTRY

Work Measurement

Some Research Studies
A. Battersby

S. Eilon, R. I. Hall, J. R. King

A. M. Lee

K. B. Haley

A. N. Dudley 


\section{Systems Analysis Frameworks}

Alec M. Lee, м.A. 
ISBN 978-1-349-00516-1 ISBN 978-1-349-00514-7 (eBook)

DOI 10.1007/978-1-349-00514-7

(C) A. M. Lee 1970

Softcover reprint of the hardcover 1st edition 1970 978-0-333-07798-6

First published by Macmillan and Co Ltd 1970

SBN 333077989

All rights reserved. No part of this publication may be reproduced or transmitted, in any form or by any means, without permission.

\section{Published by}

MACMILLAN AND CO LTD

London and Basingstoke

Associated companies in New York, Toronto

Dublin, Melbourne, Johannesburg and Madras 
To

BARBARA JANE
gyda' $m$ holl galon

From Nature's chain whatever link you strike, Tenth or ten thousandth, breaks the chain alike. And, if each system in gradation roll Alike essential to th'amazing Whole, The least confusion but in one, not all That system only, but the Whole must fall.

-Alexander Pope, An Essay on Man. 


\section{Preface}

That the terms 'system' and 'systems analysis' and even 'management information system' are fashionable in contemporary Organisational society is undeniable. The first of them is well established and if doubts exist as to its meaning the reason is that it is used in so many varied contexts and senses. The two other terms are something else again, for both are of the class of 'OK-words' which Stephen Potter first defined in his monumental study of 'Lifemanship', as:

... words which may be brought in at any point in the conversation and used with effect because no one quite understands what they mean, albeit these words have been in use for a sufficiently long time, at any rate by Highbrowmen, say ten years, for your audience to have seen them once or twice and already felt uneasy about them.

Some degree of unease is certainly justified. For example, the term 'systems analysis' is used to mean at least four different things. First, the application of the Taylorian principles of scientific management to routine clerical operations (which in Britain is commonly called organisation and methods) may be meant. Second, it may denote the systematisation of standards, routine clerical operations (such as payroll calculations) so that they may be programmed for and implemented on a computer. Third, it frequently denotes the study of the information needs of managers and staff men and the design of computer-based processes for supplying them. Finally, at the highest level, the term is employed to mean the investigation of organisations or their parts by means of the principles of the scientific method so that concepts and models may be developed upon which systems can be based to guide management in making effective internal structural and methodological changes, and in devising sound external policies, strategies and tactics. These are very different meanings. It is the fourth which is the main concern of this book.

Inevitably any discussion of this type of systems analysis must be conducted against a background of contemporary management science and information technology. However, in this book the discussion is in terms of 
broad, general principles and concepts rather than in terms of specific techniques. Management scientists will find no theoretical sections dealing with, for example, linear programming. It is true that there are a few very brief passages about statistical sampling, the elements of statistical inference and Bayes's theorem. These have been included to illustrate discussion points and to draw the attention to them of readers who may be unaware of their significance for systems analysis. These very short passages are by no means intended to provide technical instruction. And systems analysts who view systems analysis as one of the first three types defined above will find nothing at all about the techniques of flow charting, block diagrams, decision tables, computer programming or report design. These omissions are deliberate, for in my opinion it is not for want of technical expertise that contemporary Organisations achieve disappointing results from their computer-based information systems-and it is clear that many do. It is for two other reasons which derive from an unawareness of a fundamental issue. First, many managements have failed to appreciate the importance of the connection between management science (except at the computational level of routine PERT or linear programming) and their data-processing resources. Large expenditures on the latter often are accompanied by minimal expenditures on the former. This tends to depress the conceptual level of the applications of the computers at their disposal, limiting them to elementary though voluminous data manipulation. As a corollary, many managers remain aloof from the policy and strategy of systems analysis and design. They do not appreciate and so do not realise the potential available to them. This is not only unfortunate, it is dangerous.

The fundamental issue which is so often ignored is that, as the historical record shows, conceptual and technological advances in the treatment of information imply major changes in managerial technique and corporate structure. The size, character and structure of human Organisations are affected by such advances. This theme, announced early in this book, recurs and is examined from different positions and in relation to different sets of evidence. One of the forms in which this theme appears is as the question: 'Does contemporary computer and communications technology imply greater centralisation of decision making or less?' This is an important and far-reaching question. The answer to it, in any situation, is a function of the concepts employed in applying technology to the processing of information. It is with broad issues such as this that much of this book is concerned. In order to discuss them a wide range of historical and contemporary experience is drawn upon, and this material is arranged into chapters which fall into three groups with an introduction and a postscript, as follows: 
Chapter I, Perspectives, is introductory.

Chapters 2, 3, 4 and 5 define the field of systems analysis and introduce a number of basic concepts and themes.

Chapters $6,7,8$ and 9 discuss the approaches to the solution of systems problems which have been taken in the past, develop a view of the systems approach and elaborate on the concepts of information and decision.

Chapters IO, II, I2 and I3 discuss some of the primary potential areas for systematisation in a generalised Organisation, concluding with an examination of the possibilities of integrated information systems.

Chapter I4, which is very short, may be either regarded as a postscript to this book or as an invitation to debate.

These are not, however, neat non-overlapping packages. Themes from one chapter or group appear in others, possibly in some special guise, or variant form.

Limitations of space in some instances and sheer limitations of personal knowledge in others have compressed a great deal of the material into summary, possibly truncated, outlines. However, the Appendix provides a fairly extensive list of notes on sources, references and supporting evidence. I hope that it is useful. It was my intention to exclude all mathematical symbolism from this book. However the task of expressing the concepts of Chapter 4 in English alone proved quite beyond my powers and thereafter I succumbed to the use of symbols and formulas from time to time, though I have not proved theorems or derived conclusions by mathematical arguments. Hopefully the book may be read by persons with little acquaintance with mathematics. Those who wish to pursue the mathematical aspects of the topics discussed should be able to do so by referring to books and articles listed in the Appendix and marked with an asterisk.

It has not been too difficult to indicate my indebtedness to others by means of this Appendix when written sources exist. However, I must confess my inability to identify and acknowledge everyone who has contributed ideas, counter-arguments and examples in the course of conversations and discussions during the past ten years. May I therefore be forgiven if I name only Brian Brough of BEA, Herb Hubbard of United Air Lines, John Abrams of the University of Toronto, and my colleagues in Air Canada: Roger Linder, Ivan Elce, Jack Fearnley and Bill Sadler at whose instigation I wrote a series of notes in I964-65 which have developed into this book. None of them is responsible for any errors of omission or commission that exist in it. Finally, although many examples quoted are based on work which we have carried out in Air Canada, it must be asserted 
that that corporation, to which I acknowledge my indebtedness, is in no way to be held accountable for the opinions which I have not hesitated to express in it.

As on previous occasions, I have to thank my wife, Barbara, for compiling the index and for sustaining me during those periods when the words, if they came at all, would not fall into an acceptable sequence.

A. M. L.

Westmount, Quebec

April rg69 


\section{Contents}

Preface vii

I Perspectives I

2 Systems 9

3 The Scientific Method 29

4 Concepts 52

5 Organisations 75

6 Views of Structure 89

7 Views of Operational Systems $\quad$ I02

8 The Systems Approach $\quad$ I28

9 Information, Intelligence and Decision $\quad \mathrm{I} 47$

Io Problem Recognition, Classification and Appraisal $\quad$ I66

II Planning and Programming I92

I2 Operational Control 223

I3 Integration 248

I4 A Summing Up 263

Notes and References $\quad 269$

Index $\quad 279$ 